\title{
LARVICIDAL ACTIVITY OF RIPE AND UNRIPE FRUIT PEEL OF MUSA PARADISIACA L. AGAINST THE MALARIA VECTOR ANOPHELES STEPHENSI
}

\author{
SHOYMOL JOY, MANJU MADHAVAN ${ }^{*}$ \\ Department of Botany, Vimala College (Autonomous), Thrissur 680009, India \\ "Email: manjumadhavan38@gmail.com
}

Received: 01 Oct 2021, Revised and Accepted: 24 Dec 2021

ABSTRACT

Objective: To evaluate the larvicidal activity of the ripe and unripe fruit peel of Musa paradisiaca against the larvae of the malaria vector, Anopheles stephensi. There are no published data on the effect of these Musa paradisiaca fruit peel on this mosquito, primarily responsible for indigenous malaria.

Methods: The petroleum ether, ethyl acetate, and distilled water extracts of the ripe and unripe peel of Musa paradisiaca were tested against the fourth instar larvae of Anopheles stephensi. Larvicidal bioassay followed the standard WHO protocol with slight modifications.

Results: The highest larval mortality was found in ethyl acetate ripe peel extracts. The LC 50 values of Musa paradisiaca ripe fruit peel extracts of petroleum ether and ethyl acetate against Anopheles stephensi were 3.21, $2.55 \mathrm{mg} / \mathrm{ml}$, while those of unripe fruit peel extracts were 59.82 , 48.08 $\mathrm{mg} / \mathrm{ml}$, respectively. Distilled water extract showed $14.588 \mathrm{mg} / \mathrm{ml}$ for ripe fruit peel and $14.93 \mathrm{mg} / \mathrm{ml}$ of unripe fruit peel. The LC 90 values of $M$ Musa paradisiaca ripe fruit peel extracts of petroleum ether and ethyl acetate against Anopheles stephensi were $4.8,4.19 \mathrm{mg} / \mathrm{ml}$, while those of unripe fruit peel extracts were $161.1,122.22 \mathrm{mg} / \mathrm{ml}$, respectively.

Conclusion: Musa paradisiaca fruit peels extracts showed promising larvicidal activity. Ripe fruit peels of Musa paradisiaca, which is a waste material, can be exploited as an ideal eco-friendly larvicide, which could be used as an alternative for synthetic pesticides.

Keywords: Larvicidal activity, Musa paradisiaca, Anopheles stephensi, Malarial vector

(C) 2022 The Authors. Published by Innovare Academic Sciences Pvt Ltd. This is an open access article under the CC BY license (https://creativecommons.org/licenses/by/4.0/) DOI: https://dx.doi.org/10.22159/ijpps.2022v14i2.43276. Journal homepage: https://innovareacademics.in/journals/index.php/ijpps.

\section{INTRODUCTION}

Mosquitoes have been designated as the "public enemy number one" by the World Health Organization [1]. They are capable of transmitting diseases more than any other arthropod species, and they affect millions of people around the World. They are a danger to humans and are the primary carrier of life-threatening diseases such as zika, malaria, dengue fever, yellow fever, chikungunya fever, lymphatic filariasis, and Japanese encephalitis [2, 3]. Malaria affects 40 percent of the world's population, with 300 million people afflicted each year and over one million deaths [4]. Anopheles stephensi is the primary vector of malaria in India and other West Asian countries [5]. Their native range centers on the Indian subcontinent, from which they are increasingly expanding their geographic distribution [6, 7]. Larvae of the Anopheles species are generally found indistinctly different habitats and are nocturnal, crepuscular in nature, and also transmit the filarial worm causing filariasis [8]. WHO considers the management of Anopheles stephensi as a serious challenge to malaria management putting urban dwellers at a substantially higher and potentially novel risk of malaria transmission $[9,10]$.

Larvicides are used to kill mosquito larvae in the breeding habitat before they develop into adult mosquitos and spread. While larvicides are effective at controlling mosquitos in their breeding sites, they harm beneficial and non-target species [11]. Prolonged use of synthetic pesticides like organophosphates (chlorpyrifos, temephos, and fenthion) and insect growth regulators (diflubenzuron and methoprene) has initiated many detrimental consequences on humans and the environment $[3,12]$.

Phytochemicals with mosquitocidal potential are now recognized as potent alternative insecticides for replacing synthetic insecticides in mosquito control programs due to their excellent larvicidal, pupicidal, and adulticidal properties [13]. Since ancient times, plant components, ingredients, and secondary metabolites of plant origin have been used in pest control [4]. Many studies on plant extracts have been conducted worldwide to screen the larvicidal properties. Certain natural plant compounds are not only a source of new insecticides and insect repellents but are also botanical chemical derivatives that are environmentally friendly than synthetic chemicals [14]. In India, in recent years, much effect has been focused on the exploration of bioactive, chemical compounds from indigenous plants for mosquito control.

Musa paradisiaca is a perennial tree-like herb widely distributed in moist tropics. Due to enriched food value and versatile medicinal value banana is one of the most important fruits and vegetable crops of India. Banana peel is a waste material usually thrown off from the banana industry. Moreover, previous studies on leaves methanol and $95 \%$ ethanol extracts of Musa paradisiaca against III instar larvae of Anopheles stephensi and Aedes aegypti showed promising larvicidal activity $[15,16]$.

Thus, in this particular study, we are making use of the waste material, banana peel. The study assesses the larvicidal ability of extracts of banana fruit ripe and unripe peel against malaria vectors, in light of a growing interest in developing plant-based insecticides as an alternative to chemical insecticides.

\section{MATERIALS AND METHODS}

\section{Plant samples}

Ripe and unripe fruits of the Musa paradisiaca were purchased from the local market. The material was authenticated by Dr. Sheeja T Tharakan, Department of Botany, Vimala College (Autonomous), Thrissur India. Voucher specimens (Vr. No. VCTBH0301) have been deposited in the laboratory of Botany, Vimala College (Autonomous), Thrissur India.

\section{Preparation of crude extract of banana peels}

Fresh ripe and unripe peels of banana fruit were manually separated from the whole fruits and chopped into small pieces of approximately $1 \mathrm{~cm}$ size using a sharp razer. The chopped material is further dried (7-15) days in the shade at the environmental temperature, $27-37^{\circ} \mathrm{C}$, and was powdered mechanically using a commercial electrical stainless steel blender and extracted with solvents. The crude extract was prepared by dissolving $25 \mathrm{~g}$ of the dried powder in $250 \mathrm{ml}$ of 
solvents namely distilled water, ethyl acetate (Qualigens), petroleum ether (Qualigens), and the filtrate was taken after one week. The total filtrate was concentrated by evaporation on a water bath at a temperature of $40-50{ }^{\circ} \mathrm{C}$ to render the thick extracts of petroleum ether, ethyl acetate, and distilled water and later stored in the refrigerator at $5{ }^{\circ} \mathrm{C}$. From the stock solution, 0.3125 to $10 \mathrm{mg} / \mathrm{ml}$ concentrations were prepared in dechlorinated tap water. Polysorbate 80 (Qualigens) was used as an emulsifier at the concentration of $0.05 \%$ in the final test solution. The control was set up with acetone, dechlorinated tap water, and polysorbate 80 .

\section{Larvicidal activity}

\section{Test mosquitoes}

The mosquito larvae were collected from the stagnant pond water surrounding the campus of our college, Vimala College, Thrissur, and were identified by Dr. Aneesh E. M, Dept. of Zoology, St. Joseph College, Irinjalakkuda as Anopheles stephensi. The colonies of mosquitoes were maintained and all the experiments were carried out at $30-35{ }^{\circ} \mathrm{C}$ and $60 \%-80 \%$ relative humidity with a photoperiod of $12 \mathrm{~h}$ light followed by $12 \mathrm{~h}$ dark (12L: 12D). Larvae were reared in white plastic trays containing tap water [13]. Dog biscuits were added to each tray for two weeks to feed the mosquitoes to increase their breeding population.

\section{Larvicidal bioassay}

The larvicidal bioassay was assessed by the WHO standard protocol [17] with slight modifications. For bioassay test, the larvae were taken in five batches of twenty in $250 \mathrm{ml}$ of water with the desired plant extract concentration $(10 \mathrm{mg} / \mathrm{ml}, 5 \mathrm{mg} / \mathrm{ml}, 2.5 \mathrm{mg} / \mathrm{ml}, 1.25 \mathrm{mg} / \mathrm{ml}$, 0.625 and $0.3125 \mathrm{mg} / \mathrm{ml}$ ). Polysorbate 80 (Qualigens) is used as an emulsifier at a concentration of $0.05 \%$ in the final test solution. The control was set up with acetone, dechlorinated tap water, and polysorbate 80 . All the experiments were conducted in triplicate and control was performed at parallel conditions for each series of experiments. No food was provided for the larvae. Larvae were considered dead if they were unarousable within a period, even when gently probed. Larval mortality was recorded after every $3 \mathrm{~h}$ of the exposure until $24 \mathrm{~h}$ and their mortality rate was evaluated [18].

\section{Statistical analysis}

The larvicidal activities of all these extracts were calculated by preparing a concentration versus mortality rate graph. The Statistical analysis of this experimental data was performed using the computer software MS Excel 2003 to find out the $\mathrm{LC}_{50}, \mathrm{LC}_{90}$ lethal dose, and standard error through probit analysis at $n=5$ [18].

\section{RESULTS AND DISCUSSION}

The environmental safety of an insecticide is considered to be of paramount importance and should not cause mortality on the nontarget organism to be acceptable [19]. Mosquito larvae control using plant-based phytochemicals is considered a good alternative to synthetic chemicals. A large number of plant extracts have been reported to have mosquitocidal or repellant activities against mosquito vectors, but very few plant products have shown the practical utility of mosquito control [20].

The present study indicates that the ripe and unripe peel extracts of Musa paradisiaca exhibited potent lethality against the third instar larvae of Anopheles stephensi. Ripe peel distilled water extracts of Musa paradisiaca were found to be more potent and showed 100\% mortality from a $1.25 \mathrm{mg} / \mathrm{ml}$ concentration. Ethyl acetate and petroleum ether ripe extracts showed $100 \%$ mortality at 5 and 10 $\mathrm{mg} / \mathrm{ml}$ concentrations. Ethyl acetate extract at a lower concentration of $1.25 \mathrm{mg} / \mathrm{ml}$ and $2.5 \mathrm{mg} / \mathrm{ml}$ killed $20 \%$ and $80 \%$ larval population when exposed to $24 \mathrm{~h}$. On the other hand, in the unripe peel extracts, no larvicidal activity was observed till $5 \mathrm{mg} / \mathrm{ml}$ concentration in petroleum ether and ethyl acetate extracts (fig. 2). Ripe peel distilled water extracts showed $100 \%$ mortality at $10 \mathrm{mg} / \mathrm{ml}$ concentration whereas at $5 \mathrm{mg} / \mathrm{ml}$ and $2.5 \mathrm{mg} / \mathrm{ml}$ showed $80 \%$ and $55 \%$ mortality. Ripe peel extracts showed increased lethality than to unripe peel extracts.

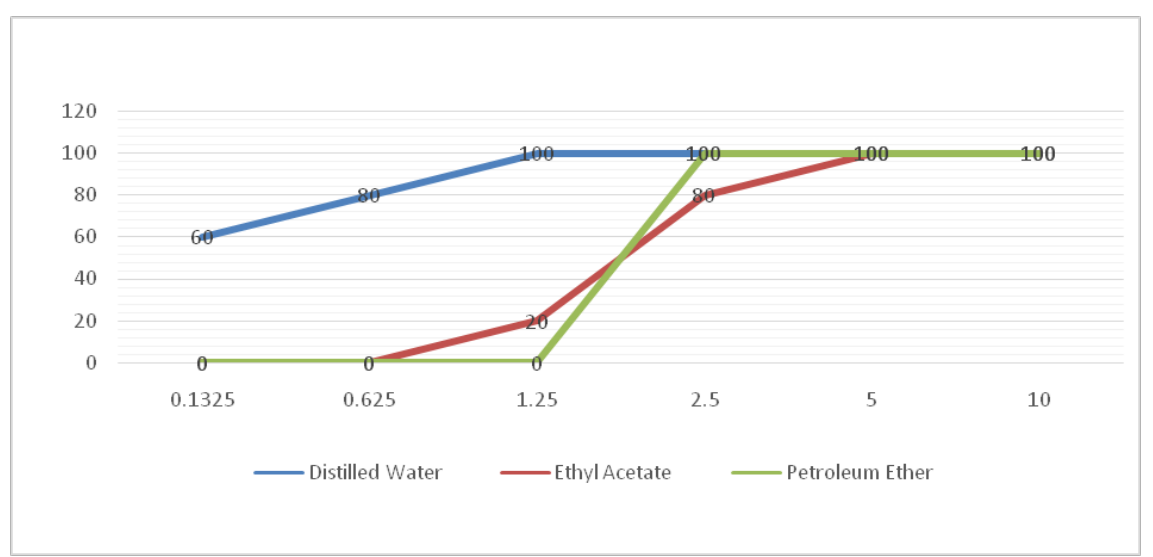

Fig. 1: Mean percentage mortality of ripe extracts at different concentrations against early 3rd instars of Anopheles stephensi within $24 \mathrm{~h}$

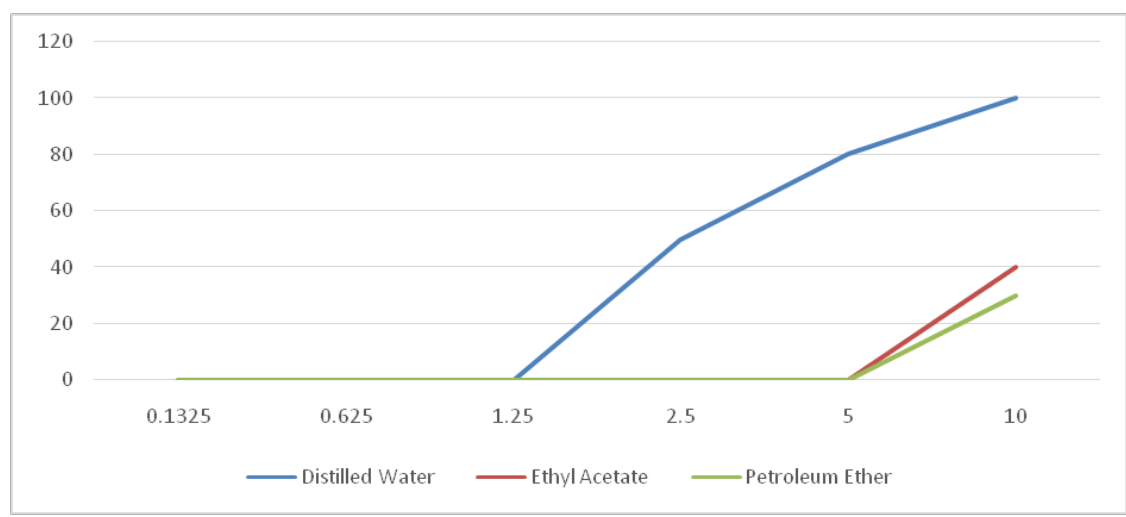

Fig. 2: Mean percentage mortality of unripe extracts at different concentrations against early 3rd instars of Anopheles stephensi within $24 \mathrm{~h}$ 
The $\mathrm{LC}_{50}$ values of Musa paradisiaca ripe fruit peel extracts of petroleum ether, ethyl acetate, and distilled water against Anopheles stephensi were $3.20,61.2$, and $14.58 \mathrm{mg} / \mathrm{ml}$, while those of unripe fruit peel extracts were 59.82, 59.82, and $14.93 \mathrm{mg} / \mathrm{ml}$ respectively (table 1). An almost similar result in LC 50 and LC 90 values were observed in the unripe peel extracts of petroleum ether and ethyl acetate. On comparing the $\mathrm{LC}_{50}$ and $\mathrm{LC}_{90}$ values of both ripe peel extracts, ethyl acetate extract shows the highest mortality percentage. Distilled water extracts of ripe and unripe peel similar results are observed.

Table 1: Larvicidal potential of the ripe and unripe extracts against third instars of Anopheles stephensi

\begin{tabular}{lll}
\hline Extracts & LC $_{\mathbf{5 0}} \mathbf{S E}$ & LC $_{\mathbf{9 0} \pm \mathbf{S E}}$ \\
\hline Ripe peel in petroleum ether & $3.20+0.815$ & $5.36+0.385$ \\
Unripe peel in petroleum ether & $59.82+1.79$ & $212.79+1.74$ \\
Ripe peel in ethyl acetate & $61.2+0.85$ & $88.09+1.14$ \\
Unripe peel in ethyl acetate & $59.82+0.78$ & $212.79+0.14$ \\
Ripe peel in distilled water & $14.58+5.75$ & $51.77+1.24$ \\
Unripe peel in distilled water & $14.93+0.65$ & $44.13+1.73$ \\
\hline
\end{tabular}

Control-Nil Mortality, LC50 Lethal Dose 50 concentration which kills 50\% of the exposed larval population; LC 90 Concentration which kills $90 \%$ of the exposed larval population SE standard error at $n=5$

Studies of Mary (2018), probit analysis revealed that the ethanolic extract of Musa acuminata ripe fruit peel against Aedes aegypti exhibited 100 percent mortality at 700 ppm after less than 1 hour of exposure [21]. In another study, aqueous extracts from Musa paradisiaca peduncle showed $100 \%$ larvicidal property at $0.5 \mathrm{mg} / \mathrm{ml}$ concentration within 24 $\mathrm{h}$ against Aedes mosquito species [22]. Among the seaweed extracts, Caulerpa racemosa showed toxicity against $4^{\text {th }}$ instar larvae of Anopheles stephensi with an $\mathrm{LC}_{50}$ value of $0.0661 \mu \mathrm{g} / \mathrm{ml}$ [23]. The crude dichloromethane extract of Nyctanthus arbor-tristis leaves was effective $\left(\mathrm{LC}_{50}, 114.56 \mathrm{mg} / \mathrm{l} ; \mathrm{LC}_{90}, 367 \mathrm{mg} / \mathrm{l}\right)$ against $4^{\text {th }}$ instar larvae of Anopheles stephensi [24]. The study of ethyl acetate extract of Musa paradisiaca flowers tested against $4^{\text {th }}$ instar larvae of Anopheles vagus showed $65 \%$ mortality [25]. Ethanolic extract of Citrus sinensis, [26], the methanol crude extract of Artemisia nilagirica [27], hexane, chloroform, acetone, methanol, and water extracts of Morinda citrifolia leaf [28], methanol extract of the root of Asparagus racemosus [29], observed against the larvae of Anopheles stephensi suggests the potential use of plant-based phytochemicals to be used as an ideal eco-friendly approach for the control of the vector control programs.

The study has opened up prospects for large-scale extraction of active ingredients of plant origin for effective mosquito control. The present study highlights the conversion of ripe and unripe banana peel produced and dumped as a waste product in municipal landfills, resulting in a major environmental hazard, as a novel product in the larvicidal study. Again this study gains significance as the ripe peels of Musa paradisiaca, which are found to be more effective, are perennially available in large quantities.

\section{CONCLUSION}

The present study revealed that Musa paradisiaca peels have the potential to be included in the formulations of new and safe control products against mosquito vectors. Further studies on the extraction procedure, larvicidal mode of action, their effects on non-target organisms, and formulations for improving their insecticidal potency are to be carried out for their standardization. This can lead to characterizing the active constituents responsible for their larvicidal properties.

\section{ACKNOWLEDGEMENT}

Authors would like to express their ineffable thanks and due reverence for Dr. Sr. Beena Jose, Principal, Vimala College (Autonomous) Thrissur for providing the facility to carry out the project. We also express our indebtedness to the DST FIST Lab, DBT Star College Scheme, and to the Department of Botany, Vimala College (Autonomous) Thrissur for the constant support. Also, we express our sincere gratitude towards Assistant professor, Dr. Aneesh E. M, Department of Zoology, St. Joseph's College, Irinjalakkuda for his guidance in identifying the mosquito species.

\section{FUNDING}

Nil

\section{AUTHORS CONTRIBUTIONS}

Manju Madhavan designed the experiment and is involved in the interpretation of data. Shoymol Joy carried out the experimental work, analysis of data, and draft manuscript preparation. The authors went through the final manuscript.

\section{CONFLICT OF INTERESTS}

The authors declare that they have no conflict of interest

\section{REFERENCES}

1. WHO. Report of the WHO Informal Consultation on the evaluation and testing of insecticides. Geneva, Switzerland: World Health Organization; 1996.

2. Benelli G, Duggan MF. Management of arthropod vector dataSocial and ecological dynamics facing the One Health perspective. Acta Trop. 2018;182:80-91. doi: 10.1016/j.actatropica.2018.02.015, PMID 29454734.

3. Ghosh A, Chowdhury N, Chandra G. Plant extracts as potential mosquito larvicides. Indian J Med Res. 2012;135(5):581-98. PMID 22771587.

4. Mukadam M. Larvicidal activity of some plant extracts against mosquitoes. Int J Trend Res. 2010;4(1):22-4.

5. Mittal PK, Subbarao SK. Prospectus of using herbal products in mosquito control. ICMR Bull. 2003;33:1-10.

6. Carvalho DO, Capurro ML. Genetic control of malaria and dengue. 4th ed. Cambridge: Academic Press; 2016. p. 409-22.

7. Kiszewski A, Mellinger A, Spielman A, Malaney P, Sachs SE, Sachs J. A global index representing the stability of malaria transmission. Am J Trop Med Hyg. 2004;70(5):486-98. doi: 10.4269/ajtmh.2004.70.486, PMID 15155980.

8. Dean M. Lymphatic filariasis, the quest to eliminate, Bulletin a 4000 y Old Disease. Publishing Company, Hollis N. H; 2001.

9. Sinka ME, Bangs MJ, Manguin S, Chareonviriyaphap T, Patil AP, Temperley WH, Gething PW, Elyazar IR, Kabaria CW, Harbach RE, Hay SI. The dominant Anopheles vectors of human malaria in the Asia-Pacific region: occurrence data, distribution maps and bionomic precis. Parasit Vectors. 2011;4:89. doi: 10.1186/1756-3305-4-89. PMID 21612587.

10. WHO. Vector alert: Anopheles stephensi invasion and spread: the Horn of Africa, the republic of Sudan and surrounding geographical areas, and Sri Lanka: information note. Geneva, Switzerland: World Health Organization; 2019.

11. Govindarajan M. Larvicidal efficacy of Ficus benghalensis L. plant leaf extracts against Culex quinquefasciatus Say, Aedes aegypti L. and anopheles stephensi L. (Diptera: Culicidae). Eur Rev Med Pharmacol Sci. 2010;14(2):107-11. PMID 20329569.

12. Tiwary M, Naik SN, Tewary DK, Mittal PK, Yadav S. Chemical composition and larvicidal activities of the essential oil of zanthoxylum armatum DC (Rutaceae) against three mosquito vectors. J Vector Borne Dis. 2007;44(3):198-204. PMID 17896622.

13. Bagavan A, Rahuman AA. Evaluation of the larvicidal activity of medicinal plant extracts against three mosquito vectors. Asian Pac J Trop Med. 2011;4(1):29-34. doi: 10.1016/S19957645(11)60027-8. PMID 21771411.

14. Cantrell CL, Pridgeon J, Fronczek FR, Becnel J. Structure-activity relationship studies on natural cudesmanolides from Inula 
helenium as toxicants against Aedes aegypti larvae and adults. Chem Biod. 2005; 7:1681-97.

15. AV, NS, AU. Larvicidal activity of some medicinal plant extracts against malaria vector anopheles stephensi. Res J Parasitol. 2008;3(2):50-8. doi: 10.3923/jp.2008.50.58.

16. de Omena MC, Navarro DM, de Paula JE, Luna JS, Ferreira de Lima MR, Sant'Ana AE. Larvicidal activities against Aedes aegypti of some Brazilian medicinal plants. Bioresour Technol. 2007;98(13):2549-56. doi: 10.1016/j.biortech.2006.09.040, PMID 17137781.

17. WHO. Instructions for determining the susceptibility or resistance of mosquito larvae to insecticides. Geneva, Switzerland: World Health Organization; 1981.

18. Singha S, Chandra G. Mosquito larvicidal activity of some common spices and vegetable waste on Culex quinquefasciatus and Anopheles stephensi. Asian Pac J Trop Med. 2011;4(4):28893. doi: 10.1016/S1995-7645(11)60088-6, PMID 21771472.

19. Kabaru JM, Gichia L. Insecticidal activity of extracts derived from different parts of the mangrove tree Rhizophora mucronata (Rhizophoraceae) Lam. against three arthropods. Afr J Sci Technol. 2001;2(2):44-9. doi: 10.4314/ajst.v2i2.44668.

20. Sun L, Dong H, Guo C, Qian J, Sun J, Ma L, Zhu C. Larvicidal activity of extracts of Ginkgo biloba exocarp for three different strains of Culex pipiens pallens. J Med Entomol. 2006;43(2):258-61. doi: 10.1603/00222585(2006)043[0258:laoeog]2.0.co;2, PMID 16619608.

21. Arizo MA M. Ripe banana peel wastes for a mosquito-free environment. Int J Waste Resour. 2018;8:2252-3.

22. Rathy MC, Sajith U, Harilal CC. Larvicidal efficacy of medicinal plant extracts against the vector mosquito Aedes albopictus. Int J Mosq Res. 2015;2(2):80-2.

23. Ali MYS, Ravikumar S, Beula JM. Mosquito larvicidal activity of seaweeds extracts against Anopheles stephensi, Aedes aegypti and Culex quinquefasciatus. Asian Pac J Trop Dis. 2013;3(3):196-201. doi: 10.1016/S2222-1808(13)60040-7.

24. Patil SV, Patil CD, Salunkhe RB, Salunke BK. Larvicidal activities of six plants extracts against two mosquito species, Aedes aegypti and Anopheles stephensi. Trop Biomed. 2010;27(3):360-5. PMID 21399575.

25. Bagavan A, Rahuman AA. Evaluation of the larvicidal activity of medicinal plant extracts against three mosquito vectors. Asian Pac J Trop Med. 2011;4(1):29-34. doi: 10.1016/S19957645(11)60027-8, PMID 21771411.

26. Murugan K, Mahesh Kumar PM, Kovendan K, Amerasan D, Subrmaniam J, Hwang JS. Larvicidal, pupicidal, repellent and adulticidal activity of Citrus sinensis orange peel extract against Anopheles stephensi, Aedes aegypti and Culex quinquefasciatus (Diptera: Culicidae). Parasitol Res. 2012;111(4):1757-69. doi: 10.1007/s00436-012-3021-8, PMID 22797605.

27. Panneerselvam C, Murugan K, Kovendan K, Mahesh Kumar PM. Mosquito larvicidal, pupicidal, adulticidal, and repellent activity of Artemisia nilagirica (Family: Compositae) against Anopheles stephensi and Aedes aegypti. Parasitol Res. 2012;111(6):224151. doi: 10.1007/s00436-012-3073-9, PMID 22903417.

28. Kovendan K, Murugan K, Shanthakumar SP, Vincent S, Hwang JS Larvicidal activity of Morinda citrifolia L.(Noni)(Family: Rubiaceae) leaf extract against Anopheles stephensi, Culex quinquefasciatus, and Aedes aegypti. Parasitol Res. 2012;111(4):1481-90. doi: 10.1007/s00436-012-2984-9, PMID 22740293.

29. Govindarajan M, Sivakumar R. Ovicidal, larvicidal and adulticidal properties of Asparagus racemosus (Willd.) (Family: Asparagaceae) root extracts against filariasis (Culex quinquefasciatus), dengue (Aedes aegypti) and malaria (Anopheles stephensi) vector mosquitoes (Diptera: Culicidae). Parasitol Res. 2014;113(4):1435-49. doi: 10.1007/s00436-014-3784-1, PMID 24488078. 